ORIGINAL ARTICLE

\title{
Downhill skiing injury fatalities among children
}

\author{
H Xiang, L Stallones, G A Smith
}

Injury Prevention 2004;10:99-102. doi: 10.1136/ip.2003.004655

\begin{abstract}
Objective: Young skiers are at increased risk for injury, however, epidemiological data on skiing related fatal injuries among child skiers are scarce. This study aimed to provide information needed to develop injury control and prevention programs.

Design and setting: Study subjects came from Colorado, USA and were identified using a death certificate based surveillance system. Fatal injuries were limited to events that occurred at established commercial ski resorts in Colorado, and subjects were classified as child skiers (0-17 years) or adult skiers ( $\geqslant 18$ years). Main outcome measure: Type and external cause, time, and week day of injury, gender and residency of the decedents.

Results: During the study period from 1980-2001, 149 fatal injuries associated with downhill skiing were identified; 21 (14.1\%) occurred among child skiers aged $\leqslant 17$ years. The age of the youngest decedent was 7 years. In females the proportion of fatal injuries among child skiers was nearly three times that of adults. Traumatic brain injuries were the leading cause of death (67\% of all deaths) among children, while multiple internal injuries and traumatic brain injuries accounted for almost equal proportions of fatal injuries among adults. Collision was the leading external mechanism of fatal injuries, accounting for more than two thirds of fatal injuries in both child and adult skiers.

Conclusions: Traumatic brain injury was the leading cause and collision was the leading external injury mechanism of fatal injuries associated with downhill skiing among child skiers. This underscores the importance of brain injury prevention strategies, including the use of ski helmets and prevention of collisions on ski slopes.
\end{abstract}

See end of article for authors' affiliations

Correspondence to: Dr Huiyun Xiang, Center for Injury Research and Children's Hospital, 700 Children's Drive, Columbus, $\mathrm{OH}$ 43205-2696, USA xiangh@pediatrics. ohio-state.edu
$\mathrm{D}$ ownhill, or alpine, skiing is a popular winter sport in the United States. According to a household based survey conducted by the National Sporting Goods Association, ${ }^{1}$ an average of 10 million people in the United States participated in alpine skiing more than once a year during 1993-97.

Injuries from sports and physical activities, often underestimated and under-researched, have captured national attention recently. ${ }^{2-4}$ According to the National Electronic Injury Surveillance System (NEISS), ${ }^{1}$ there were estimated 84200 skiing associated injuries treated in hospital emergency departments in the United States in 1997, a decline from the estimated 114400 injuries in 1993. Interestingly, head injuries associated with skiing and snowboarding have not decreased as has the total number of skiing injuries, and head injuries are still the leading cause of injury deaths occurring on ski slopes. ${ }^{5}$

Non-fatal injuries associated with skiing and snowboarding have been studied extensively both in the United States and in other countries. ${ }^{6-13}$ However, few studies have looked at fatal injuries associated with skiing. ${ }^{14-19}$ There is a consensus among investigators that young skiers are at increased risk for both fatal and non-fatal injury. ${ }^{711}$ Unfortunately, basic epidemiological data regarding skiing related fatal injuries among child skiers are scarce. A major reason for the lack of this critical information is that fatal injuries associated with skiing are rare among general population (2.5-2.9 deaths per one million skiers), therefore, such data for child skiers are not readily available. Using death certificate data from 1980-2001, we intend to describe skiing related fatal injuries among child skiers in Colorado. Injury characteristics and circumstances are compared for child skiers and adult skiers to identify unique injury patterns among child skiers with an intention to provide information for promotion of injury control and prevention among this vulnerable population.

\section{METHODS}

\section{Data collection}

Study subjects were identified using a special fatal skiingand snowboarding related injury surveillance system in Colorado. Causes of death on the death certificate were reported by attending physicians, medical examiners, or coroners. A revision of the coding structure occurred in 1988 which resulted in non-specific codes for place of injury, however, a detailed description of the injury circumstances was added to the electronic death record. In this study, "place of injury" on the death certificate was used to identify injury deaths related to skiing prior to 1989, and for the years 19892001, the description of how the injury occurred was searched electronically for the occurrence of character strings such as "ski", "skier", "skiing", "snow", "snowboarding", and "avalanche" to identify skiing related fatal injuries. Death certificates of potential skiing related fatal injuries were then reviewed manually to determine whether or not the decedent was skiing at the time when the fatal event occurred. The death certificates were also reviewed to identify the place of skiing activities, such as within boundary of commercial ski resorts, outside commercial ski resorts areas, or cross country skiing areas.

\section{Case definition}

For this study, a downhill skiing related fatal injury was defined as a fatal injury that occurred to an individual who was skiing at a commercial ski resort in Colorado. Fatal injuries that occurred outside an established commercial ski resort area and those related to cross country skiing were excluded from analysis.

Abbreviations: CPSC, Consumer Product Safety Commission; TBI, traumatic brain injury 


\section{Statistical analysis}

Cases were divided into two age groups: child skiers (0-17 years) and adult skiers ( 18 years and older). The following variables were used in our study: age and gender of decedent, state of residence, week day of injury event, time of injury, injury description, underlying cause of death, and time between the initial injury event and the pronounced death.

Differences in injury proportions between child skiers and adult skiers were assessed for statistical significance with Mantel-Haenszel $\chi^{2}$ test, or with Fisher's exact two tailed test when at least one expected cell size was $<5$. Data were analyzed using SAS statistical software version 8.2. ${ }^{20}$ Statistical significance was considered for $\mathrm{p}<0.05$.

\section{RESULTS}

During the study period, a total of 149 fatal injuries associated with downhill skiing were identified in Colorado; $21(14.1 \%)$ injuries occurred among child skiers aged 17 years or younger. The age of the youngest decedent was 7 years, and the highest proportion of total fatal injuries $(24.2 \%)$ occurred among skiers aged 18-24 years (fig 1).

The demographics of the decedents and the comparisons of characteristics of fatal injuries between child skiers and adult skiers are shown in table 1. Among the 21 child skiers, $47.6 \%$ (10 cases) were female compared with $16.4 \%$ (21 cases) female among 128 adult skiers $(p=0.001)$. Child decedents were more likely to be residents of states other than Colorado $(66.7 \%)$ than were adult decedents $(60.2 \%)$. However the difference was not statistically significant $(\mathrm{p}=0.698)$.

The greatest number of fatal injuries among child skiers (six deaths, 28.6\%) occurred between 1:00 pm and 3:00 pm, while the greatest number of fatal injuries among adult skiers (28 deaths, 21.7\%) occurred between 11:00 am and 1:00 pm. Approximately the same percentage (around 30\%) of child and adult decedents was pronounced dead at the scene.

As shown in table 2, a significantly higher percentage of child skiers died from traumatic brain injury (TBI) (66.7\%) than adult skiers $(42.2 \%)$. The difference was statistically significant $(\mathrm{p}=0.05)$. About $76 \%$ of child deaths $(n=16)$ were due to collisions, compared with approximately $69 \%$ of adult deaths $(n=88)$. The majority of fatal collisions were with trees for both child decedents $(52.4 \%)$ and adult decedents $(57.0 \%)$.

\section{DISCUSSION}

In this report, 20 years of data from the Colorado statewide skiing related and snowboarding related fatal injury surveillance system were used to compare fatal injuries associated with downhill skiing between child skiers and adult skiers. Findings from this study highlight the unique characteristics of downhill skiing related fatal injuries to child skiers.
Table 1 Characteristics of downhill skiing related fatal injuries among child skiers $(n=21)$ and adult skiers $(n=128)$

\begin{tabular}{|c|c|c|c|}
\hline & $\begin{array}{l}\text { No }(\%) \text { child } \\
\text { skiers }\end{array}$ & $\begin{array}{l}\text { No }(\%) \text { adult } \\
\text { skiers }\end{array}$ & p Value \\
\hline Gender & & & 0.001 \\
\hline Male & $11(52.4)$ & $107(83.6)$ & \\
\hline Female & $10(47.6)$ & $21(16.4)$ & \\
\hline State of residency & & & $0.698^{*}$ \\
\hline Colorado & $6(28.6)$ & 46 (35.9) & \\
\hline Other states & $14(66.7)$ & $77(60.2)$ & \\
\hline Foreigners & $1(4.8)$ & $5(3.9)$ & \\
\hline Day of injury & & & $0.859^{*}$ \\
\hline Monday & $2(11.8)$ & $15(11.7)$ & \\
\hline Tuesday & $3(14.3)$ & $19(14.8)$ & \\
\hline Wednesday & $4(19.1)$ & $23(18.0)$ & \\
\hline Thursday & $1(4.8)$ & $15(11.7)$ & \\
\hline Friday & $4(19.1)$ & 17 (13.3) & \\
\hline Saturday & $6(28.6)$ & $24(18.8)$ & \\
\hline Sunday & $1(4.8)$ & $15(11.7)$ & \\
\hline Time of injury & & & $0.645^{\star}$ \\
\hline $9: 00$ am-10:59 am & $4(19.1)$ & $22(17.1)$ & \\
\hline $11: 00 \mathrm{am}-12: 59 \mathrm{pm}$ & $5(23.8)$ & $28(21.7)$ & \\
\hline $1: 00$ pm-2:59 pm & $6(28.6)$ & $20(15.5)$ & \\
\hline $3: 00 \mathrm{pm}-4: 59 \mathrm{pm}$ & $3(14.3)$ & $21(17.1)$ & \\
\hline $5: 00 \mathrm{pm}-8: 59 \mathrm{pm}$ & $1(4.8)$ & $4(3.1)$ & \\
\hline $9: 00 \mathrm{pm}-8: 59 \mathrm{am}$ & $0(-)$ & $6(4.7)$ & \\
\hline Unknown & $2(9.5)$ & $27(20.9)$ & \\
\hline Hours from injury to death & & & $0.939 *$ \\
\hline 0 & $6(28.6)$ & 40 (31.3) & \\
\hline $0.1 \sim<1$ & $2(9.5)$ & $11(8.6)$ & \\
\hline $1 \sim<2$ & 4 (19.1) & $20(15.6)$ & \\
\hline $2+$ & 7 (33.3) & 48 (37.5) & \\
\hline Unknown & $2(9.5)$ & $9(7.0)$ & \\
\hline
\end{tabular}

Among child skiers, females accounted for a significantly greater proportion of fatal injuries, and TBI was the leading cause of death. Collision, often with a tree, was the leading mechanism of fatal injuries, accounting for more than two thirds of fatal injuries in both child and adult skiers.

Findings from previous studies regarding gender and skiing related injury risk have been inconclusive. Some studies reported that the majority of fatal injuries occur to males, ${ }^{16}{ }^{17}$ while others reported that the injury risk is higher for females or same for both sexes. ${ }^{13}{ }^{15}$ Data from the National Ski Area Association indicated that in Colorado in 1996, males constituted $61 \%$ of all skiers and snowboarders. ${ }^{5}$ In our study, $47.6 \%$ of child decedents were girls while only $16.4 \%$ of adult decedents were females. However, without detailed age distribution data of skiing participants for the study period, it is impossible to make the conclusion that the mortality rates were similar or different among male and female skiers for

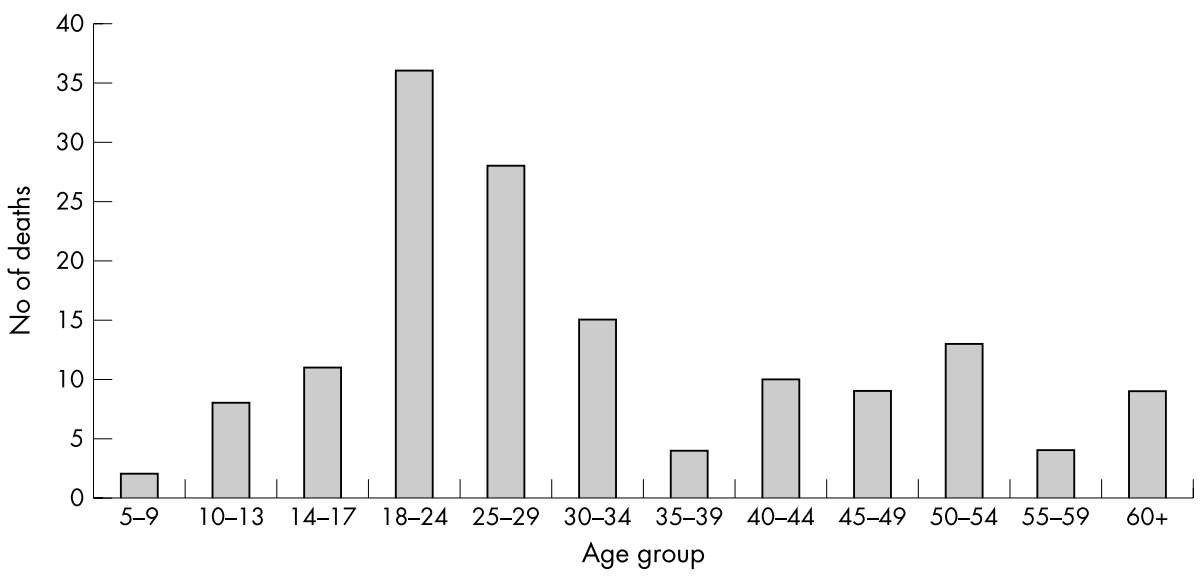

Figure 1 Age distribution of skiing related fatal injuries in Colorado, 1980-2001. 
Table 2 Type of downhill skiing related fatal injuries among child skiers $(n=21)$ and adult skiers $(n=128)$

\begin{tabular}{llll}
\hline & $\begin{array}{l}\text { No }(\%) \text { child } \\
\text { skiers }\end{array}$ & $\begin{array}{l}\text { No (\%) adult } \\
\text { skiers }\end{array}$ & p Value \\
\hline $\begin{array}{llll}\text { Type of injury } \\
\text { Head trauma }\end{array}$ & $14(66.7)$ & $54(42.2)$ & 0.05 \\
Multiple internal trauma & $6(28.6)$ & $59(46.1)$ & \\
Other & $1(4.8)$ & $15(11.7)$ & \\
Injury description & $16(76.2)$ & $88(68.7)$ & $0.82^{*}$ \\
Collisiont & $11(52.4)$ & $73(57.0)$ & \\
Tree & $1(4.8)$ & $10(7.8)$ & \\
Object & $2(9.5)$ & $3(2.3)$ & \\
Other skier & $2(9.5)$ & $2(1.6)$ & \\
$\quad$ Ski lift post & $2(9.5)$ & $9(7.0)$ & \\
Fall & $2(9.5)$ & $22(17.2)$ & \\
General skiing injury event & $1(4.8)$ & $9(7.0)$ & \\
Other & & & \\
\hline
\end{tabular}

*Fisher's exact two sided test.

†Total collision number was used for Fisher's exact test.

both age groups. Goulet et al suggested that behavioral differences between boys and girls on risk taking, and the expected increases in associated injuries, do not actually manifest in adolescents or young adults. ${ }^{13}$ That might partially explain why a significant gender specific difference in mortality is absent among child skiers while such difference is more apparent among adult skiers. However, because of the small number of cases reviewed and the lack of denominator data, the majority of studies that analyzed fatal skiing injuries, ${ }^{14-18}$ including the current study, had limited statistical power to evaluate gender specific differences.

A significant difference was observed between child skiers and adult skiers with regard to TBI in our study. A significantly higher proportion of child skiers than adult skiers sustained TBIs. Although previous studies identified TBI as the leading cause of skiing related fatal injuries, ${ }^{14-18}$ the small number of fatal injuries reviewed in earlier reports prevented separate analysis for child skiers. Therefore, the higher proportion of TBI among child skiers has not been previously reported.

The high proportion of TBI among child skiers in this study suggests that child skiers in particular may benefit from the use of ski helmets. However, because of lack of information regarding helmet use in our database, we were unable to directly evaluate the effectiveness of helmets in preventing or reducing TBI among skiers. Several studies have emphasized the significance of TBI resulting from collisions among skiers and snowboarders, and have suggested that protective helmets might reduce TBI morbidity and mortality. ${ }^{1} 510151621$ A thorough literature review conducted by the United States

\section{Key points}

- Traumatic brain injury was the leading cause of downhill skiing related fatal injuries among child skiers 7-17 years of age.

- Collisions, often with trees, were the leading external mechanism for downhill skiing related injuries for both child skiers and adult skiers.

- Effectiveness of ski helmets in preventing traumatic brain injuries among child skiers needs to be studied further.

- Lack of detailed exposure information (number of skiers and total skiing hours) is one of the major limitations.
Consumer Product Safety Commission (CPSC) concluded that helmets would potentially prevent $44 \%$ of head injuries in skiers and snowboarders overall, and 53\% of head injuries in skiers and snowboarders younger than 15 years. ${ }^{1}$ Brown et al strongly advocate ski helmet use among child and adolescent skiers because of the high proportion of child skiers who suffered from TBI. ${ }^{22}$ Unfortunately, the effectiveness of ski helmets in preventing TBI has not been as well researched as has that of helmets in other sports, such as bicycle riding. ${ }^{23-24}$

This study is subject to the following limitations. The primary limitation was the lack of exposure information in this study. Traditionally, skier visits or lift tickets sold are used as the denominators when injury rates are calculated. Such data are often available from ski resorts or ski resorts associations. ${ }^{19}$ However, detailed data by age group or gender are often not available, therefore it is impossible to calculate injury rates by participants' demographics. In our results, there was a significant difference between child skiers and adult skiers in the proportion of injuries by gender, but for the reason of lack of exposure information, we could not make the conclusion that the mortality rates were similar or different among male and female skiers. Second, there was a possibility of misclassification of leading causes of death. It was unclear from the death certificates how medical examiners or coroners decided the leading cause of deaths when fatal injuries damaged multiple organs. Third, for $20.9 \%$ of fatal injuries that occurred among adult skiers and 9.5\% among child skiers, the injury time was unknown, which might distort the time distribution of those fatal injuries reported here. Finally, only skiing related fatal injuries that occurred in Colorado were analyzed. People would assume that such data at national level would have more observations and thus more statistical power. The CPSC estimated that there are about 24 skiing and snowboarding related deaths per year in the United States. ${ }^{1}$ Skiing and snowboarding related deaths in Colorado (about 10 cases per year) account for approximately half of total skiing related and snowboarding related deaths in the United States. Although it is possible to use national data from the CPSC's Death Certificate Data Base, more than 10 years' data will be needed to generate more than 200 cases, and small number issues will still exist to some extents.

Even with these limitations, our findings indicated that TBI was the leading cause, and collisions, often with trees, were the leading external mechanism of fatal injuries among child skiers. This underscores that TBI prevention strategies, including the use of ski helmets and prevention of collisions on ski slopes, are crucial in injury control and prevention among child skiers.

\section{ACKNOWLEDGEMENTS}

At the time of the study, Dr Huiyun Xiang was with the Colorado Department of Public Health and Environment (CDPHE). We thank several CDPHE former staff members who tracked skiing and snowboarding injuries in Colorado before Dr Huiyun Xiang arrived at the CDPHE.

This work was funded in part by the Centers for Disease Control and Prevention, The National Center for Injury Prevention and Control R49/CCR811509. Its contents are solely the responsibility of the authors and do not necessarily represent the official views of the Centers for Disease Control and Prevention.

\section{Authors' affiliations}

H Xiang, G A Smith, Center for Injury Research and Policy, Columbus Children's Research Institute and Columbus Children's Hospital, College of Medicine and Public Health, The Ohio State University, Columbus, Ohio

L Stallones, Colorado Injury Control Research Center, Department of Psychology, Colorado State University, Fort Collins, Colorado 


\section{REFERENCES}

1 US Consumer Product Safety Commission. Skiing helmets: an evaluation of the potential to reduce head injury. Washington, DC: US Government Printing Office, 1999

2 National Institutes of Health. Sports injuries in youth: surveillance strategies. Bethesda, MD: National Institutes of Health, 1992.

3 National Center for Injury Prevention and Control. CDC injury research agenda. Atlanta, GA: Centers for Disease Control and Prevention, 2002.

4 Conn JM, Annest JL, Gilchrist J. Sports and recreation related injury episodes in the US population. Inj Prev 2003;9:117-23.

5 Levy S, Hawkes A, Hemminger L, et al. Analysis of head injuries among skiers and snowboarders. J Trauma 2002;53:695-704.

6 Jaffin B. An epidemiologic study of ski injuries: Vail, Colorado. Mt Sinai J Med $1981 ; 48: 353-9$.

7 Blitzer CM, Johnson RJ, Ettlinger CF, et al. Downhill skiing injuries in children. Am J Sports Med 1984;12:142-7.

8 Furrer $M$, Erhart $S$, Frutiger $A$, et al. Severe skiing injuries: a retrospective analysis of 361 patients including mechanism of trauma, severity of injury, and mortality. J Trauma 1995;39:737-41.

9 Macnab AJ, Cadman R. Demographics of alpine skiing and snowboarding injury: lessons for prevention programs. Inj Prev 1996;2:286-9.

10 Shorter NA, Jensen PE, Bethany JH, et al. Skiing injuries in children and adolescents. J Trauma 1996;40:997-1001.

11 Deibert MC, Aronsson DD, Johnson RJ, et al. Skiing injuries in children, adolescents, and adults. J Bone Joint Surg Am 1998;80(A1):25-32.

12 Ferrera PC, McKenna DP, Gilman EA. Injury patterns with snowboarding. Am J Emerg Med 1999;17:575-7.
13 Goulet C, Regnier G, Grimard G, et al. Risk factors associated with alpine skiing injuries in children: a case control study. Am J Sports Med 1999;27:644-50.

14 Weston JT, Moore SM, Rich TH. A five-year study of mortality in a busy ski population. J Forensic Sci 1977;22:222-30.

15 Morrow PL, McQuillen EN, Eaton LA, et al. Downhill ski fatalities: the Vermont experience. J Trauma 1988;28:95-100.

16 Sherry E, Clout L. Deaths associated with skiing in Australia: a 32-year study of cases from the Snowy Mountains. Med J Aust 1988;149:615-8.

17 Tough SC, Butt JC. A review of 19 fatal injuries associated with downhill skiing. Am J Forensic Med Pathol 1993;14:12-16.

18 Tough SC, Butt JC. A review of 19 fatal injuries associated with backcountry skiing. Am J Forensic Med Pathol 1993;14:17-21.

19 Xiang HY, Stallones L. Deaths associated with snow skiing in Colorado: 1980-191 to 2000-2001 ski seasons. Injury 2003;34:892-96.

20 SAS Institute Inc. SAS/STAT user's guide, version 8. Cary, NC: SAS Institute Inc, 2000.

21 Jenkins $\mathbf{R}$, Johnson RJ, Pope $M H$. Collision injuries in downhill skiing. In: Schroeder JR, Green KA, Hoersch HM, et al, eds. Ski trauma and safety. Proceedings of the Fifth International Symposium. Philadelphia: ASTM Publications, 1983:358-66.

22 Brown JM, Ramsey LC, Weiss AL. Ski helmets: an idea whose time has come. Contemp Pediatr 1997; 14:115-25.

23 Thompson RS, Rivara FP, Thompson DC. A case-control study of the effectiveness of bicycle safety helmets. N Engl J Med 1989:320:1361-7.

24 Thompson DC, Rivara FP, Thompson RS. Effectiveness of bicycle safety helmets in preventing head injuries: a case-control study. JAMA 1996;276:1968-73.

\section{PATRICIA F WALLER ENDOWMENT FUND Patricia $\mathrm{F}$ Waller}

E

riends and colleagues of Dr Patricia F Waller have established an endowment in the

University of North Carolina Injury Prevention Research Center (IPRC) to honor her as

the center's founding director. Waller died on 15 August 2003 after a long illness.

"Dr Waller exemplified the spirit of interdisciplinary collaboration and was a critical thinker whose ideas were often ahead of their time", said Dr Carol Runyan, current IPRC director and a collaborator with Waller in the early years of forming the center. "Our hope is to attract other scholars to campus who share these attributes so we can continue to celebrate the vitality and importance of her ideas and continue to innovate".

The Patricia F Waller Endowment Fund will be used to support an annual lecture in her honor to be overseen jointly by the IPRC, the UNC Highway Safety Research Center, the department of psychology, and members of the Waller family. Additional gifts will accrue in the hope that the fund will support a professorship in the field of injury control, officials said.

The IPRC is a multidisciplinary federally funded center founded in 1987 and bringing together faculty experts from numerous other schools and departments at UNC.

"An endowed professorship would not only be a significant tribute, but would ensure that there is a lasting presence at UNC for injury control, the focus of Waller's career", said Runyan, who also is professor of health behavior and health education in UNC's School of Public Health.

"In the shorter term, with the lectureship, we expect that we will sustain her enthusiasm for scholarship in this field in a very tangible way, encouraging students and faculty from diverse fields to think about this huge social problem together and find solutions that will save lives and reduce suffering-just as Pat did during her lifetime", she added.

Waller received her doctorate in psychology from UNC and worked for nearly two decades as a researcher with the UNC Highway Safety Research Center. She launched the IPRC with a vision that merged her background in traffic safety with public health perspectives on injury control. She later served as director of the University of Michigan Transportation Research Institution and professor of public health policy and administration. She retired to Chapel Hill in 1999.

Gifts to the Patricia F Waller Endowment Fund can be made in care of UNC's Office of University Development, PO Box 309, Chapel Hill, NC 27514. Contact Carol Runyan at +19199662251, carol_runyan@unc.edu or Karen Demby+1919843 3530,karen_demby@ med.unc.edu-Chrys Bullard, Office of University Development. 